Corresponding authors: michael.hildebrand@unimelb .edu.au; i.scheffer@unimelb .edu.au; Tony.Penington@rch org.au

(c) 2021 Green et al. This article is distributed under the terms of the Creative Commons

Attribution-NonCommercial License, which permits reuse and redistribution, except for commercial purposes, provided that the original author and source are credited.

Ontology terms: focal seizures with impairment of consciousness or awareness; generalized tonic seizures; intellectual disability; mild; linear nevus sebaceous

Published by Cold Spring Harbor Laboratory Press

doi:10.1101/mcs.a006133

\section{Identification of a recurrent mosaic KRAS variant in brain tissue from an individual with nevus sebaceous syndrome}

Timothy E. Green, ${ }^{1}$ Duncan MacGregor, ${ }^{2}$ Susan M. Carden, ${ }^{3,4,5}$ Rebekah V. Harris, ${ }^{1}$ Chelsee A. Hewitt, ${ }^{6}$ Samuel F. Berkovic, ${ }^{1}$ Anthony J. Penington, ${ }^{5,7,8,10}$ Ingrid E. Scheffer, ${ }^{1,5,7,9,10}$ and Michael S. Hildebrand ${ }^{1,7,10}$
Abstract Nevus sebaceous syndrome (NSS) is a rare, multisystem neurocutaneous disorder, characterized by a congenital nevus, and may include brain malformations such as hemimegalencephaly or focal cortical dysplasia, ocular, and skeletal features. It has been associated with several eponyms including Schimmelpenning and Jadassohn. The isolated skin lesion, nevus sebaceous, is associated with postzygotic variants in HRAS or KRAS in all individuals studied. The RAS proteins encode a family of GTPases that form part of the RAS/MAPK signaling pathway, which is critical for cell cycle regulation and differentiation during development. We studied an individual with nevus sebaceous syndrome with an extensive nevus sebaceous, epilepsy, intellectual disability, and hippocampal sclerosis without pathological evidence of a brain malformation. We used high-depth gene panel sequencing and droplet digital polymerase chain reaction (PCR) to detect and quantify RAS/MAPK gene variants in nevus sebaceous and temporal lobe tissue collected during plastic and epilepsy surgery, respectively. A mosaic KRAS c.34G > T; p.(Gly12Cys) variant, also known as G12C, was detected in nevus sebaceous tissue at $25 \%$ variant allele fraction (VAF), at the residue most commonly substituted in KRAS. Targeted droplet digital PCR validated the variant and quantified the mosaicism in other tissues. The variant was detected at $33 \%$ in temporal lobe tissue but was absent from blood and healthy skin. We provide molecular confirmation of the clinical diagnosis of NSS. Our data extends the histopathological spectrum of KRAS G12C mosaicism beyond nevus sebaceous to involve brain tissue and, more specifically, hippocampal sclerosis.

\section{INTRODUCTION}

Nevus sebaceous is a sporadic cutaneous disorder characterized by benign skin lesions predominately of the scalp and face that occurs in 1 in 1000 newborns (Rogers 1992; Sugarman

\footnotetext{
${ }^{10}$ These authors contributed equally to this work.
} 
2007). The lesions are hamartomas comprising epidermal, sebaceous, and apocrine elements that form hairless, yellow-orange plaques of varying size and shape (Fig. 1C,D). Benign or malignant secondary tumors may develop in the nevi (Moody et al. 2012). Nevus sebaceous syndrome (NSS) refers to a rare multisystem disorder in which the nevus sebaceous occurs in association with cerebral, ocular, or skeletal abnormalities. In individuals with NSS, the most frequently reported central nervous system (CNS) finding is of hemimegalencephaly, which is typically ipsilateral to the nevus (Pavlidis et al. 2012), with more localized malformations in some individuals (Pascual-Castroviejo and Ruggieri 2008; Pepi et al. 2021). Hippocampal sclerosis and focal cortical dysplasia type la have also been described in one individual (Pepi et al. 2021). The term nevus sebaceous syndrome has been associated
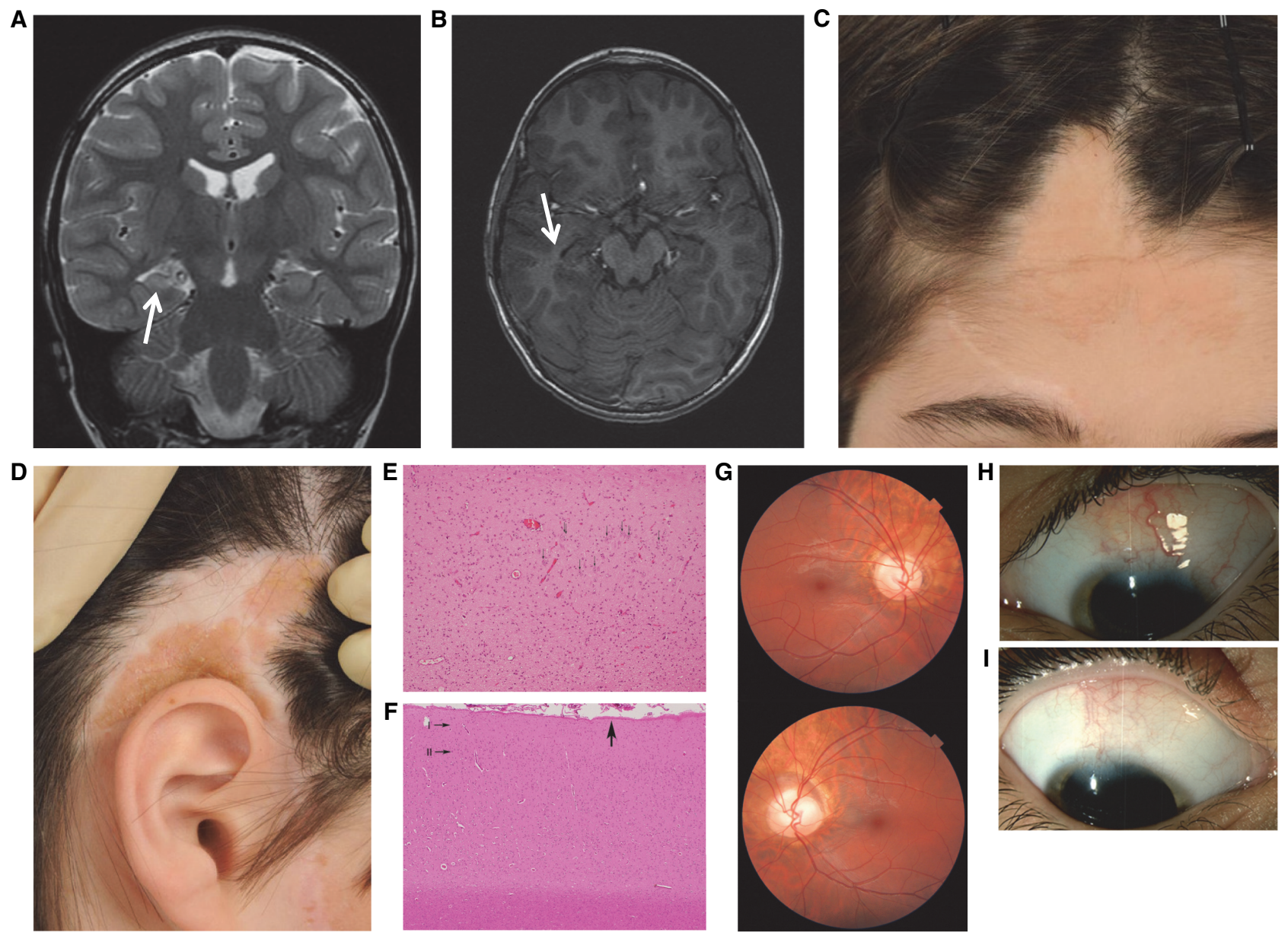

Figure 1. Histopathological evaluation of the individual with nevus sebaceous syndrome (NSS). (A) Coronal fast spin echo image showing a small right hippocampus with a subtle increase in T2 signal, consistent with hippocampal sclerosis (arrow). (B) Tilted axial FSPGR (fast spoiled gradient echo) image showing a small right hippocampus (arrow); there is no radiological evidence of cortical dysplasia. $(C, D)$ Photographs showing sebaceous nevus on the scalp and face. (E) Hematoxylin and eosin (H\&E) stain; 20x original objective. Hippocampal cortex showing intact neurons (CA3) in the right half of the field (arrows) with abrupt disappearance and transition to mesial temporal sclerosis in the left half of the field. $(F)$ H\&E stain; 10x original objective. Temporal cortex representative of multiple sections, with preserved horizontal lamination; molecular (I) and external granular (II) laminae only shown. Subpial gliosis seen in protracted seizures in general is shown with a broad arrow. $(G)$ Images of fundi showing anomalous optic nerves. $(H, I)$ Photographs of lesions affecting the limbus, sclera, and conjunctiva of both eyes. 
with a variety of eponyms and synonyms including Schimmelpenning syndrome, Jadassohn sebaceous nevus syndrome, linear sebaceous nevus syndrome, SchimmelpenningFeuerstein-Mims syndrome, and epidermal nevus syndrome (Schimmelpenning 1957).

Both nevus sebaceous and NSS result from genetic mosaicism, restricted to the skin in isolated nevus sebaceous and extending into other organs in NSS. Specifically, postzygotic variants in the RAS/MAPK pathway genes HRAS, KRAS, and NRAS cause isolated nevus sebaceous or NSS (Groesser et al. 2012; Kuroda et al. 2015). In isolated nevus sebaceous, $95 \%$ of lesions are caused by mosaic HRAS variants with the c.37G > C; p.(Gly13Arg), also known as G13R, being the most frequently identified variant accounting for $>90 \%$ of individuals. Mosaic KRAS variants have been identified in the remaining $5 \%$ of isolated nevus sebaceous individuals (Groesser et al. 2012). A minority of sebaceous nevi harbor double-mosaic RAS variants with indistinguishable phenotypes from those with single RAS variants (Groesser et al. 2012). Conversely, in the rarer individuals with NSS, KRAS appears to be more common in 13 reported individuals in whom the molecular basis has been determined with the identification of postzygotic variants. Of those 13 reported individuals with NSS, KRAS variants account for nine, with HRAS variants in three and NRAS in one (Groesser et al. 2012; Sun et al. 2013; Kuroda et al. 2015; Igawa et al. 2016; Jiang et al. 2017; Mitchell et al. 2018; Chacon-Camacho et al. 2019; Nagatsuma et al. 2019; De los SantosLa Torre et al. 2020; Pan et al. 2020; Pepi et al. 2021). Pathogenic variants tend to be recurrent affecting residues functionally conserved across all RAS proteins (Groesser et al. 2012). Notably, recurrent variants within the conserved Glycine 12, Glycine 13, and Glutamine 61 residues of the RAS proteins are a well-established cause of several cancer subtypes (Pylayeva-Gupta et al. 2011). Functional analyses have confirmed these variants confer constitutive activation of the MAPK and PI3K-AKT pathways (Groesser et al. 2012). In addition to its association with nevus sebaceous, low-level mosaic KRAS variants at $<10 \%$ variant allele frequency (VAF) have also been found in the CNS where they are associated with brain and spinal cord arteriovenous malformations (Hong et al. 2019; Priemer et al. 2019). Although most identified variants in RAS genes are postzygotic, germline variants have been reported. One such example was an individual with neuro-cardio-facio-cutaneous features including severe epilepsy and hippocampal sclerosis found to have a de novo germline KRAS c.468C > G; p.(F156L) variant (Søvik et al. 2007). Here we provide further evidence for the role of KRAS in the genetic architecture of NSS by describing an individual with these features as a result of the recurrent somatic KRAS G12C mutation.

\section{RESULTS}

\section{Medical History}

A 21 -yr-old man was born with extensive head and neck nevus sebaceous lesions with the typical appearance of yellow, slightly raised plaques (Fig. 1C,D). He had several separate lesions: extending $17 \mathrm{~cm}$ from the scalp to anterior to the right ear, superior and posterior to the right ear, on the forehead, and extending from the right supraorbital region to the right side of the nose. He was mildly hirsute without dysmorphic features. He received a range of laser therapies and underwent surgical resections of the nevi with tissue available from a resection in 2012 for molecular testing.

On the first day of life, he presented with an episode of apnea and further 10-sec episodes of cyanosis over the next few days. By age 3 mo, he had focal impaired awareness seizures with loss of awareness, generalized stiffening, and dry retching. Seizures occurred in clusters, and he was commenced on phenytoin. At $3 \mathrm{yr}$, he had focal impaired awareness seizures that began with an aura in which he called his mother and clung onto her, followed by staring straight ahead, pallor, and oral automatisms. A cluster of seizures culminated in 
a 25-min focal to bilateral tonic-clonic seizure. Cranial magnetic resonance imaging (MRI) showed right hippocampal sclerosis and a bulky right amygdala without evident cortical dysplasia (Fig. 1A,B). His seizures remained drug-resistant, and at $4 \mathrm{yr}$, he underwent a right anterior temporal lobectomy. He was seizure-free until age 12 when he had tonic-clonic status epilepticus controlled with diazepam. He was subsequently seizure-free until the time of writing at age 21 . Carbamazepine was ceased at age 6 , then recommenced from age 12 , and he remains on monotherapy.

His early development was mildly delayed with walking at $18 \mathrm{mo}$, and he had behavioral problems in early childhood that improved after epilepsy surgery. He had mild intellectual disability with a Wechsler Intelligence Scale for Children IV Full Scale IQ of 59 (0.3rd centile) and attended a mixture of mainstream school with integration aide support and special school. Ophthalmological examination showed that in both eyes the superior limbus was abnormal with an associated symmetrical orange, vascularized lesion involving the conjunctiva, and sclera (Fig. 1H,I). Despite bilateral anomalous optic discs with parts appearing colobomatous, his visual acuity was 20/16 in each eye (Fig. 1G). At age 16, he had a left superior incongruous homonymous quadrantanopia likely due to the right anterior temporal lobectomy at age 5 . He was too young to perform the test before surgery. General and neurological examinations were otherwise normal. He had no family history of cutaneous lesions, brain malformation, or epilepsy.

Histopathological analysis of his temporal lobe showed prominent neuronal loss from the cornu ammonis, consistent with hippocampal sclerosis, without obvious tumor or dysplasia (Fig. 1E). The neocortex showed focal subpial gliosis. Analysis of the resected nevus showed moderate papillomatosis, acanthosis, and hyperkeratosis with a few poorly formed pilosebaceous units, consistent with epidermal nevus (Fig. 1F).

\section{Genomic Analyses}

Chromosomal microarray analysis of saliva-derived DNA excluded any significant genomic imbalances. We subsequently performed massively parallel sequencing on genomic DNA isolated from fresh-frozen nevus sebaceous tissue. We used a targeted gene panel to interrogate the coding regions of 19 candidate genes, which identified the mosaic KRAS variant NM_033360.2:c.34G > T; p.(G12C), also known as G12C, at a VAF of $26.0 \%$ in sebaceous tissue (Table 1).

To validate and quantify the distribution of this mosaic KRAS G12C variant, we analyzed DNA from several tissues using Sanger sequencing and droplet digital polymerase chain reaction (ddPCR). In addition to DNA from the nevus sebaceous, we isolated DNA from formalin-fixed paraffin-embedded (FFPE) temporal lobe tissue, as well as from healthy skin, blood, and saliva. The mosaic KRAS variant was validated within the nevus sebaceous tissue by Sanger sequencing. The KRAS variant was also detected in the temporal lobe brain tissue (Fig. 2A). We subsequently quantified this mosaic variant by performing ddPCR, which confirmed the KRAS variant was present with a VAF of $25.1 \%$ in the nevus sebaceous tissue and a VAF of $33.2 \%$ in the brain tissue (Fig. 2B). The KRAS variant was not detected in blood-, saliva-, or healthy skin-derived DNA samples by ddPCR or Sanger sequencing (Fig. 2).

Table 1. Recurrent KRAS variant detected in the individual with nevus sebaceous syndrome (NSS)

\begin{tabular}{cccccccc}
\hline Gene & Chromosome & HGVS DNA reference & HGVS protein reference & Variant type & Predicted effect & dbSNP/dbVar ID & Genotype \\
\hline KRAS & Chr12 & $\begin{array}{c}\text { NM_033360.2: } \\
\text { c.34G }>\text { T }\end{array}$ & p.(Gly12Cys)(G12C) & Missense & Substitution & rs121913530 & Mosaic \\
\hline
\end{tabular}


A

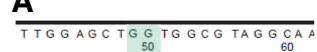

Nevus sebaceous

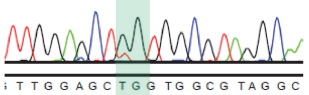

Brain

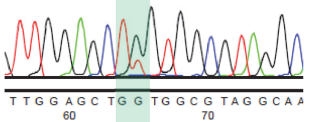

Healthy skin

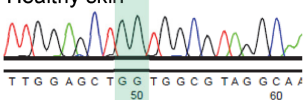

Blood

Mhandwhande

$\frac{\overline{T T G G A G C T G G T G G C G T A G G C A}}{{ }_{60}}$

Saliva

Mandwhwown

\section{B}

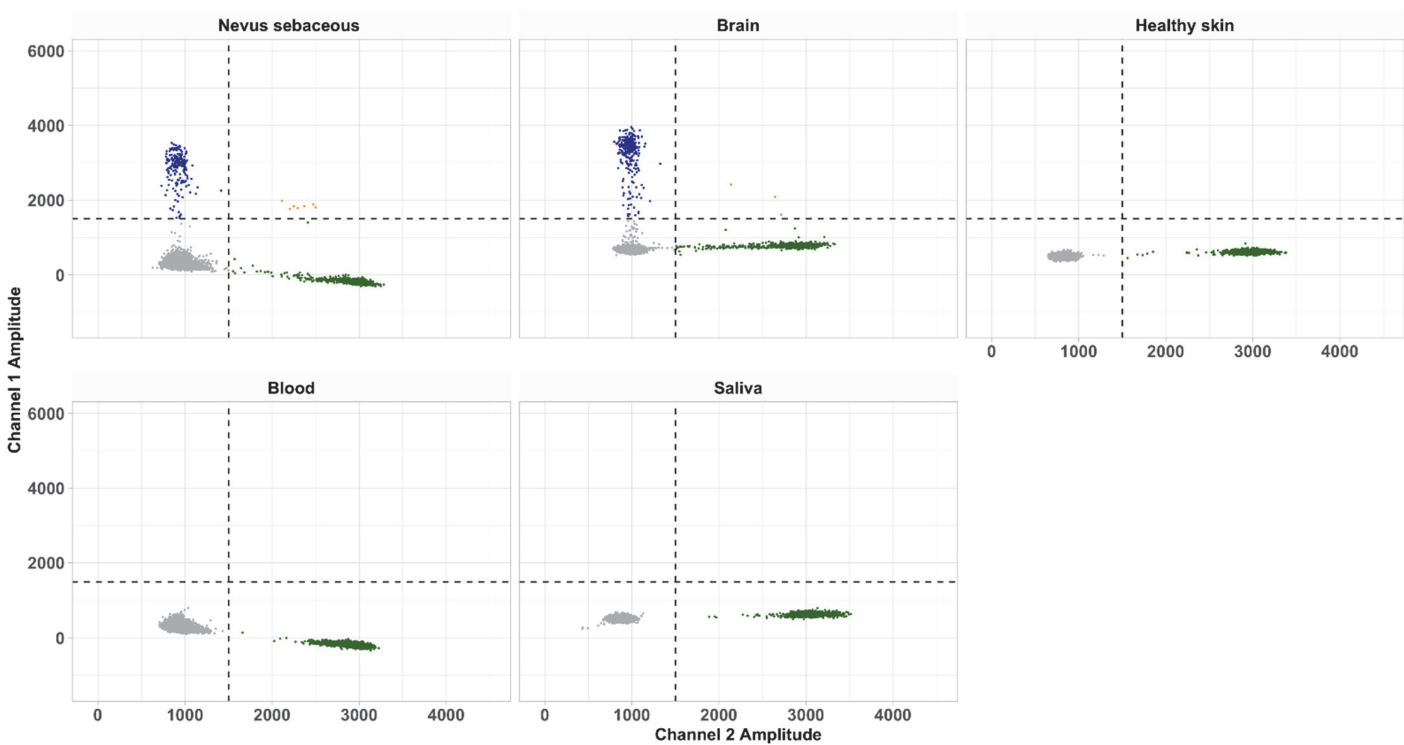

Figure 2. Molecular evaluation of mosaicism in the individual with nevus sebaceous syndrome (NSS). (A) Sanger sequencing of the KRAS c.34G > T; p.(G12C) mosaic variant. (B) The level of mosaicism of the KRAS G12C variant was quantified by droplet digital polymerase chain reaction (ddPCR) in nevus sebaceous, brain, normal skin, blood, and saliva DNA. (Blue droplets) Mutant DNA copies, (green droplets) wild-type DNA copies, (gray droplets) droplets without DNA copies, (orange droplets) droplets with multiple DNA copies. The $x$-axis shows the amplitude of wild-type fluorescent probe; the $y$-axis shows the amplitude of mutant fluorescent probe.

\section{DISCUSSION}

The detection of HRAS and KRAS variants within cutaneous tissues of individuals with both isolated nevus sebaceous and NSS has provided important insights into the molecular etiology of these disorders (Groesser et al. 2012). Here, we extend the molecular pathology with the identification of a recurrent postzygotic mosaic KRAS variant within extracutaneous tissues in the CNS in an individual with NSS. Our findings in this individual are consistent with a recent individual (Pepi et al. 2021), confirming the hypothesis that NSS is caused by mosaic variants distributed across multiple systems; in contrast to the localized mosaic variants found in isolated sebaceous nevi (Groesser et al. 2012). These results suggest that mosaic variants in NSS are likely to arise earlier in development in common progenitor cells that give rise to multiple tissue lineages. Our results are analogous to the relationship between Sturge-Weber syndrome, a severe neurocutaneous disorder, which is associated with a characteristic facial capillary malformation, a port-wine stain, and isolated nonsyndromic portwine stain. Both are associated with the recurrent mosaic GNAQ c.548G > A; p.(R183Q) pathogenic variant. In Sturge-Weber syndrome, the variant is present within affected brain and skin endothelial cells, whereas in isolated nonsyndromic port-wine stain, the variant is only present in skin cells (Shirley et al. 2013; Nakashima et al. 2014; Huang et al. 2017; Hildebrand et al. 2018).

KRAS variants are commonly detected in cancers with the most frequent mutations arising at the G12 amino acid position in exon 2 (Pylayeva-Gupta et al. 2011). Postzygotic mosaic $K R A S$ variants have also been identified in skin samples from individuals with both isolated nevus sebaceous and NSS (Groesser et al. 2012; Nagatsuma et al. 2019; Pan et al. 2020). In addition, mosaic KRAS variants have been identified in vascular malformations, most frequently 
within arteriovenous malformations of the brain and spinal cord with venous and lymphatic malformations less frequently reported (Jiang et al. 2017; Hong et al. 2019; Priemer et al. 2019; Ten Broek et al. 2019). The phenotypic spectrum associated with mosaic KRAS variants extends further to individuals with keratinocytic epidermal nevus syndrome (KENS), somatic overgrowth, encephalocraniocutaneous lipomatosis, renovascular hypertension, Wilms' tumors, and Gorham-Stout disease (Farschtschi et al. 2015; McDonell et al. 2018; Nozawa et al. 2020; Chang et al. 2021). In contrast, activating germline KRAS variants are an infrequent cause of RASopathies, specifically cardio-facio-cutaneous syndrome and Noonan syndrome; however, these variants are located elsewhere in the gene, in positions not typically associated with cancer (Schubbert et al. 2006, 2007; Søvik et al. 2007). Functional analysis of brain endothelial cells derived from arteriovenous malformations demonstrated that KRAS G12 variants promote ectopic activation of downstream signaling pathways including MAPK-ERK (Nikolaev et al. 2018). This provides a potential pathway for precision therapies as multiple inhibitors targeting the KRAS G12C variant are currently under development (Canon et al. 2019; Hallin et al. 2020). Efficacy has recently been demonstrated in clinical trials of individuals with non-small-cell lung cancer (NSCLC) (Rosen 2021; Skoulidis et al. 2021), although some cancers are resistant to such therapies (Awad et al. 2021).

We provide molecular confirmation of a mosaic KRAS variant within affected temporal lobe tissue in an individual with NSS. Our results demonstrate that the isolated cutaneous lesion of nevus sebaceous and the more severe neurocutaneous disorder of NSS, have the same molecular cause. The variable phenotypic spectrum is likely to be influenced by the precise timing and cell of origin of the mutation, with variants arising very early in fetal life, producing wider tissue expression and more severe phenotypic consequences (Groesser et al. 2012; Poduri et al. 2013). Detailed molecular characterization of NSS provides opportunities to explore new therapeutic pathways for these individuals, which have the potential to be transformational in the setting of cognitive impairment secondary to brain involvement.

\section{METHODS}

\section{Samples}

Genomic DNA was extracted from all tissues using the QIAGEN All Prep DNA/RNA, QIAamp DNA Maxi Kit, or QIAamp DNA FFPE Tissue Kit according to the manufacturer's instructions.

\section{Chromosomal Microarray}

The Illumina Infinium GSA-24 v2.0 BeadChip was used to perform genome-wide copy-number variation (CNV) and loss of heterozygosity $(\mathrm{LOH})$ screening at a reportable resolution of $0.2 \mathrm{Mb}$ on saliva-derived DNA. The data was analyzed using NxClinicalv6.0 (BioDiscovery) using genome reference sequence NCBI37/hg19.

\section{Gene Panel Sequencing}

Massively parallel sequencing was performed in the Pathology Department at the Peter MacCallum Cancer Centre. Amplicon-based next-generation sequencing (NGS) was performed on nevus sebaceous DNA followed by targeted sequencing on an Illumina MiSeq platform with $2 \times 150$-bp reads. Amplicons targeted coding regions of the following genes: AKT1, ALK, BRAF, CDKN2A, EGFR, ERBB2, FGFR2, FGFR3, KIT, KRAS, MAP2K1, MET, NRAS, PDGFRA, PIK3CA, PTEN, RAC1, RNF43, and TP53. Aligned reads and called variants were analyzed using PathOS v1.5. 
Competing Interest Statement I.E.S. has served on scientific advisory boards for UCB, Eisai, GlaxoSmithKline, BioMarin, Nutricia, Rogcon, Chiesi, Encoded Therapeutics, Knopp Biosciences, and Xenon Pharmaceuticals; has received speaker honoraria from GlaxoSmithKline, UCB, BioMarin, Biocodex, Chiesi, Liva Nova, and Eisai; has received funding for travel from UCB, Biocodex, GlaxoSmithKline, Biomarin, and Eisai; has served as an investigator for Zogenix, Zynerba, Ultragenyx, GW Pharma, UCB, Eisai, Xenon Pharmaceuticals, Anavex Life Sciences, Ovid Therapeutics, Epigenyx, Encoded Therapeutics, and Marinus; and has consulted for Zynerba Pharmaceuticals, Atheneum Partners, Ovid Therapeutics, Care Beyond Diagnosis, Epilepsy Consortium, and UCB. She may accrue future revenue on pending patent WO61/010176 (filed: 2008): Therapeutic Compound; has a patent for SCN1A testing held by Bionomics Inc and licensed to various diagnostic companies; and has a patent molecular diagnostic/theranostic target for benign familial infantile epilepsy (BFIE) [PRRT2] 2011904493 \& 2012900190 and PCT/AU2012/ 001321 (TECH ID:2012-009)

Received July 25, 2021; accepted in revised form

September 29, 2021.

\section{Droplet Digital Polymerase Chain Reaction}

Custom Affinity Plus Mini Probes and primers were ordered from Integrated DNA Technologies, Inc. to validate and quantify the mosaic KRAS variant. Droplet generation, PCR cycling, and droplet reading were performed according to the manufacturer's recommendations (Bio-Rad). Briefly, probes and primers were mixed with $2 x$ ddPCR Supermix (No dUTPs) for probes (Bio-Rad) at $250 \mathrm{nM}$ and $900 \mathrm{nM}$ final concentrations for each probe and each of the primers, respectively, and mixed with $10 \mathrm{ng}$ of DNA sample to a final volume of $23 \mu \mathrm{L}$. Twenty microliters of reactions were loaded in an eight-channel droplet generator cartridge (Bio-Rad), and droplets were generated with $70 \mu \mathrm{L}$ of droplet generation oil (BioRad) by using the manual QX200 Droplet Generator. Following droplet generation, samples were manually transferred to a 96-well PCR plate, heat-sealed, and amplified on a C1000 Touch thermal cycler using the following cycling conditions: $10 \mathrm{~min}$ at $95^{\circ} \mathrm{C}$ for one cycle, followed by 45 cycles of $30 \mathrm{sec}$ at $94^{\circ} \mathrm{C}$ and of $60 \mathrm{sec}$ at $55^{\circ} \mathrm{C}$, one cycle for $10 \mathrm{~min}$ at $98^{\circ}$ $\mathrm{C}$ and $4^{\circ} \mathrm{C}$ hold. Post-PCR products were read on the QX200 droplet reader (Bio-Rad) and analyzed using the QuantaSoft Analysis Pro software. Variant allele fractions were derived from the "Fractional Abundance" output in the Quantasoft software. Custom in-house Rscripts were utilized to generate ddPCR 2D plots.

\section{Sanger Sequencing}

Gene-specific primers were used to amplify and sequence the KRAS variant (forward primer: 5'-ATCGTCAAGGCACTCTTGC-3', reverse primer: 5'-AACCTTATGTGTGACATGTTCTAA$\left.3^{\prime}\right)$. Amplification reactions were cycled using a standard protocol on a Veriti Thermal Cycler (Applied Biosystems) for $1 \mathrm{~min}$ at $60^{\circ} \mathrm{C}$ annealing temperature. Bidirectional sequencing was completed with a BigDyeTM v3.1 Terminator Cycle Sequencing Kit (Applied Biosystems) according to the manufacturer's instructions. Sequencing products were resolved using a 3730 XL DNA Analyzer (Applied Biosystems). All sequencing electropherograms were compared to published cDNA sequences; nucleotide changes were detected using Codon Code Aligner (CodonCode Corporation).

\section{ADDITIONAL INFORMATION}

\section{Data Deposition and Access}

We do not have consent to deposit genomics data on publicly accessible databases. The identified KRAS variant has been publicly listed in the Leiden Open Variation Database (LOVD; https://www.lovd.nl/) under Variant number 0000796579.

\section{Ethics Statement}

We studied an individual with NSS with nevus sebaceous, focal epilepsy, intellectual disability, and hippocampal sclerosis. The Human Research Ethics Committee of Austin Health, Melbourne, Australia (Project No. H2007/02961) approved this study. Written informed consent was obtained from the parents of the individual for participation in the study and the publication of clinical photographs.

\section{Acknowledgments}

We thank the individual and his family for their participation in this study.

\section{Author Contributions}

M.S.H., I.E.S., and A.J.P. initiated and directed the project. T.E.G., C.A.H., and M.S.H. performed molecular genetics experiments. S.M.C., R.V.H., S.F.B., A.J.P., and I.E.S. performed 
clinical phenotyping. D.M. performed histopathological analyses. S.F.B., A.J.P., I.E.S., and M.S.H. provided equipment and reagents. T.E.G., M.S.H., A.J.P., and I.E.S. wrote the paper. All authors discussed the results and reviewed the manuscript.

\section{Funding}

This study was supported by a National Health and Medical Research Council Program Grant to I.E.S. and S.F.B., Project Grant to S.F.B., Project Grant to M.S.H., Investigator Grant and Practitioner Fellowship to I.E.S., Investigator Grant to S.F.B., and R.D. Wright Career Development Fellowship to M.S.H. A.J.P. and M.S.H. were supported by a Medical Research Future Fund (MRFF) Grant. I.E.S. was supported by an MRFF Grant. A.J.P. was supported by the Jigsaw Foundation.

\section{REFERENCES}

Awad MM, Liu S, Rybkin II, Arbour KC, Dilly J, Zhu VW, Johnson ML, Heist RS, Patil T, Riely GJ, et al. 2021. Acquired resistance to KRAS ${ }^{\mathrm{G} 12 \mathrm{C}}$ inhibition in cancer. N Engl J Med 384: 2382-2393. doi:10.1056/ NEJMoa2105281

Canon J, Rex K, Saiki AY, Mohr C, Cooke K, Bagal D, Gaida K, Holt T, Knutson CG, Koppada N, et al. 2019. The clinical KRAS(G12C) inhibitor AMG 510 drives anti-tumour immunity. Nature 575: 217-223. doi:10.1038/ s41586-019-1694-1

Chacon-Camacho OF, Lopez-Moreno D, Morales-Sanchez MA, Hofmann E, Pacheco-Quito M, Wieland I, Cortes-Gonzalez V, Villanueva-Mendoza C, Zenker M, Carlos Zenteno J. 2019. Expansion of the phenotypic spectrum and description of molecular findings in a cohort of patients with oculocutaneous mosaic RASopathies. Mol Genet Genomic Med 7: e625. doi:10.1002/mgg3.625

Chang CA, Perrier R, Kurek KC, Estrada-Veras J, Lehman A, Yip S, Hendson G, Diamond C, Pinchot JW, Tran $\mathrm{JM}$, et al. 2021. Novel findings and expansion of phenotype in a mosaic RASopathy caused by somatic KRAS variants. Am J Med Genet A 185: 2829-2845. doi:10.1002/ajmg.a.62356

De los Santos-La Torre MA, Del Águila-Villar CM, Lu-de Lama LR, Nuñez-Almache O, Chávez-Tejada EM, Espinoza-Robles OA, Pinto-lbárcena PM, Calagua-Quispe MR. 2020. Association of central precocious puberty with a rare presentation of Schimmelpenning-Feuerstein-Mims syndrome in a Peruvian girl. Case Rep Endocrinol 2020: 1-5. doi:10.1155/2020/1928121

Farschtschi S, Mautner V-F, Hollants S, Hagel C, Spaepen M, Schulte C, Legius E, Brems H. 2015. Keratinocytic epidermal nevus syndrome with Schwann cell proliferation, lipomatous tumour and mosaic KRAS mutation. BMC Med Genet 16: 1-7. doi:10.1186/s12881-015-0146-5

Groesser L, Herschberger E, Ruetten A, Ruivenkamp C, Lopriore E, Zutt M, Langmann T, Singer S, Klingseisen L, Schneider-Brachert W, et al. 2012. Postzygotic HRAS and KRAS mutations cause nevus sebaceous and Schimmelpenning syndrome. Nat Genet 44: 783-787. doi:10.1038/ng.2316

Hallin J, Engstrom LD, Hargis L, Calinisan A, Aranda R, Briere DM, Sudhakar N, Bowcut V, Baer BR, Ballard JA, et al. 2020. The KRAS ${ }^{\mathrm{G} 12 \mathrm{C}}$ inhibitor MRTX849 provides insight toward therapeutic susceptibility of KRASmutant cancers in mouse models and patients. Cancer Discov 10: 54-71. doi:10.1158/2159-8290.CD-191167

Hildebrand MS, Harvey AS, Malone S, Damiano JA, Do H, Ye Z, McQuillan L, Maixner W, Kalnins R, Nolan B, et al. 2018. Somatic GNAQ mutation in the forme fruste of Sturge-Weber syndrome. Neurol Genet 4: e236. doi:10.1212/NXG.0000000000000236

Hong T, Yan Y, Li J, Radovanovic I, Ma X, Shao YW, Yu J, Ma Y, Zhang P, Ling F, et al. 2019. High prevalence of KRAS/BRAF somatic mutations in brain and spinal cord arteriovenous malformations. Brain 142: 23-34. doi:10.1093/brain/awy307

Huang L, Couto JA, Pinto A, Alexandrescu S, Madsen JR, Greene AK, Sahin M, Bischoff J. 2017. Somatic GNAO mutation is enriched in brain endothelial cells in Sturge-Weber syndrome. Pediatr Neurol 67: 59-63. doi:10.1016/j.pediatrneurol.2016.10.010

Igawa S, Honma M, Minami-Hori M, Tsuchida E, lizuka H, Ishida-Yamamoto A. 2016. Novel postzygotic KRAS mutation in a Japanese case of epidermal nevus syndrome presenting with two distinct clinical features, keratinocytic epidermal nevi and sebaceous nevi. J Dermatol 43: 103-104. doi:10.1111/1346-8138.13153

Jiang L, Gao F, Mao S, Xu J, Jiang K. 2017. Somatic KRAS mutation in an infant with linear nevus sebaceous syndrome associated with lymphatic malformations A case report and literature review. Medicine (Baltimore) 96: e8016. doi:10.1097/MD.0000000000008016 
Kuroda Y, Ohashi I, Enomoto Y, Naruto T, Baba N, Tanaka Y, Aida N, Okamoto N, Niihori T, Aoki Y, et al. 2015. A postzygotic NRAS mutation in a patient with Schimmelpenning syndrome. Am J Med Genet A 167: 2223-2225. doi:10.1002/ajmg.a.37135

McDonell LM, Leung GK-C, Daoud H, Ip J, Chim S, Luk HM, Lan L, Boycott KM, Chung BH-Y. 2018. Mosaic KRAS mutation in a patient with encephalocraniocutaneous lipomatosis and renovascular hypertension. Am J Med Genet A 176: 2523-2527. doi:10.1002/ajmg.a.40349

Mitchell BJ, Rogers GF, Wood BC. 2018. A patient with Schimmelpenning syndrome and mosaic KRAS mutation. J Craniofac Surg 30: 184-185. doi:10.1097/SCS.0000000000004887

Moody MN, Landau JM, Goldberg LH. 2012. Nevus sebaceous revisited. Pediatr Dermatol 29: 15-23. doi:10 $.1111 / \mathrm{j} .1525-1470.2011 .01562 . x$

Nagatsuma M, Takasawa K, Yamauchi T, Nakagawa R, Mizuno T, Tanaka E, Yamamoto K, Uemura N, Kashimada K, Morio T. 2019. A postzygotic KRAS mutation in a patient with Schimmelpenning syndrome presenting with lipomatosis, renovascular hypertension, and diabetes mellitus. J Hum Genet 64: 177-181. doi:10.1038/s10038-018-0539-3

Nakashima M, Miyajima M, Sugano H, limura Y, Kato M, Tsurusaki Y, Miyake N, Saitsu H, Arai H, Matsumoto N. 2014. The somatic GNAQ mutation c.548G >A (p.R183Q) is consistently found in Sturge-Weber syndrome. J Hum Genet 59: 691-693. doi:10.1038/jhg.2014.95

Nikolaev SI, Vetiska S, Bonilla X, Boudreau E, Jauhiainen S, Jahromi BR, Khyzha N, DiStefano PV, Suutarinen S, Kiehl TR, et al. 2018. Somatic activating KRAS mutations in arteriovenous malformations of the brain. $N$ Engl J Med 378: 250-261. doi:10.1056/NEJMoa1709449

Nozawa A, Ozeki M, Niihori T, Suzui N, Miyazaki T, Aoki Y. 2020. A somatic activating KRAS variant identified in an affected lesion of a patient with Gorham-Stout disease. J Hum Genet 65: 995-1001. doi:10.1038/ s10038-020-0794-y

Pan C, Zhou X, Hong A, Fang F, Wang Y. 2020. Identification of KRAS mutation in a patient with linear nevus sebaceous syndrome: a case report. BMC Med Genomics 13: 188. doi:10.1186/s12920-02000847-1

Pascual-Castroviejo I, Ruggieri M. 2008. Schimmelpenning-Feuerstein-Mims syndrome (nevus sebaceous syndrome). In Neurocutaneous disorders phakomatoses and hamartoneoplastic syndromes (ed. Di Rocco C), Vol. 33, pp. 559-573. Springer, Vienna.

Pavlidis E, Cantalupo G, Boria S, Cossu G, Pisani F. 2012. Hemimegalencephalic variant of epidermal nevus syndrome: case report and literature review. Eur J Paediatr Neurol 16: 332-342. doi:10.1016/j.ejpn .2011 .12 .004

Pepi C, de Palma L, Trivisano M, Pietrafusa N, Lepri FR, Diociaiuti A, Camassei FD, Carfi-Pavia G, De Benedictis A, Rossi-Espagnet $C$, et al. 2021. The role of KRAS mutations in cortical malformation and epilepsy surgery: a novel report of nevus sebaceous syndrome and review of the literature. Brain Sci 11: 793. doi:10.3390/ brainsci11060793

Poduri A, Evrony G, Cai D, and Wash X, A C. 2013. Somatic mutation, genomic variation, and neurological disease. Science 341: 6141. doi:10.1126/science.1237758

Priemer DS, Vortmeyer AO, Zhang S, Chang HY, Curless KL, Cheng L. 2019. Activating KRAS mutations in arteriovenous malformations of the brain: frequency and clinicopathologic correlation. Hum Pathol 89: 3339. doi:10.1016/j.humpath.2019.04.004

Pylayeva-Gupta Y, Grabocka E, Bar-Sagi D. 2011. RAS oncogenes: weaving a tumorigenic web. Nat Rev Cancer 11: 761-774. doi:10.1038/nrc3106

Rogers M. 1992. Epidermal nevi and the epidermal nevus syndromes: a review of 233 cases. Pediatr Dermatol 9: 342-344. doi:10.1111/j.1525-1470.1992.tb00623.x

Rosen N. 2021. Finally, effective inhibitors of mutant KRAS. N Engl J Med 384: 2447-2449. doi:10.1056/ NEJMe2107884

Schimmelpenning GW. 1957. Clinical contribution to symptomatology of phacomatosis. Fortschr Geb Rontgenstr Nuklearmed 87: 716-720. doi:10.1055/s-0029-1213358

Schubbert S, Zenker M, Rowe SL, Böll S, Klein C, Bollag G, van der Burgt I, Musante L, Kalscheuer V, Wehner LE, et al. 2006. Germline KRAS mutations cause Noonan syndrome. Nat Genet 38: 331-336. doi:10.1038/ ng1748

Schubbert S, Bollag G, Lyubynska N, Nguyen H, Kratz CP, Zenker M, Niemeyer CM, Molven A, Shannon K. 2007. Biochemical and functional characterization of germ line KRAS mutations. Mol Cell Biol 27: 77657770. doi:10.1128/MCB.00965-07

Shirley MD, Marchuk DA, North PE, Cohen B, Frelin LP, Baugher JD, Comi AM, Gallione CJ, Hao T, Pevsner J. 2013. Sturge-Weber syndrome and port-wine stains caused by somatic mutation in GNAQ. N Engl J Med 368: 1971-1979. doi:10.1056/NEJMoa1213507

Skoulidis F, Li BT, Dy GK, Price TJ, Falchook GS, Wolf J, Italiano A, Schuler M, Borghaei H, Barlesi F, et al. 2021. Sotorasib for lung cancers with KRAS p.G12C mutation. N Engl J Med 384: 2371-2381. doi:10.1056/ NEJMoa2103695 
Søvik O, Schubbert S, Houge G, Steine SJ, Norgård G, Engelsen B, Njølstad PR, Shannon K, Molven A. 2007. De novo HRAS and KRAS mutations in two siblings with short stature and neuro-cardio-facio-cutaneous features. J Med Genet 44: e84. doi:10.1136/jmg.2007.049361

Sugarman JL. 2007. Epidermal nevus syndromes. Semin Cutan Med Surg 26: 221-230. doi:10.1016/j.sder .2008.03.006

Sun BK, Saggini A, Sarin KY, Kim J, Benjamin L, LeBoit PE, Khavari PA. 2013. Mosaic activating RAS mutations in nevus sebaceous and nevus sebaceous syndrome. J Invest Dermatol 133: 824-827. doi:10.1038/jid 2012.377

Ten Broek RW, Eijkelenboom A, Vleuten CJM, Kamping EJ, Kets M, Verhoeven BH, Grunberg K, Schultze Kool LJ, Tops BBJ, Ligtenberg MJL, et al. 2019. Comprehensive molecular and clinicopathological analysis of vascular malformations: a study of 319 cases. Genes Chromosomes Cancer 58: 541-550. doi:10.1002/ gcc.22739 


\section{COLD SPRING HARBOR Molecular Case Studies}

\section{Identification of a recurrent mosaic KRAS variant in brain tissue from an individual with nevus sebaceous syndrome}

Timothy E. Green, Duncan MacGregor, Susan M. Carden, et al.

Cold Spring Harb Mol Case Stud 2021, 7: a006133 originally published online October 14, 2021 Access the most recent version at doi: $10.1101 / \mathrm{mcs}$.a006133

References This article cites 39 articles, 4 of which can be accessed free at: http://molecularcasestudies.cshlp.org/content/7/6/a006133.full.html\#ref-list-1

License This article is distributed under the terms of the Creative Commons Attribution-NonCommercial License, which permits reuse and redistribution, except for commercial purposes, provided that the original author and source are credited.

Email Alerting Receive free email alerts when new articles cite this article - sign up in the box at the Service top right corner of the article or click here. 